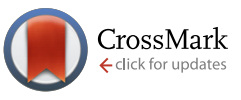

Cite this: CrystEngComm, 2015, 17, 1778

Received 19th January 2015,

Accepted 20th January 2015

\section{Polymorphism of a polymer precursor: metastable glycolide polymorph recovered via large scale high-pressure experiments $\dagger$}

\author{
Ian B. Hutchison, ${ }^{a}$ Amit Delori, ${ }^{a}$ Xiao Wang, ${ }^{\text {b }}$ Konstantin V. Kamenev, ${ }^{\text {b }}$ \\ Andrew J. Urquhart ${ }^{c}$ and lain D. H. Oswald ${ }^{\star a}$
}

DOI: $10.1039 / c 5 c e 00119 f$

www.rsc.org/crystengcomm

A novel polymorph of glycolide, the precursor to polyglycolic acid, has been observed at $0.6 \mathrm{GPa}$. Large scale high-pressure production has been performed and the seeds successfully used to aid crystallisation of the polymorph at ambient pressure. PIXEL calculations confirm the metastable nature of the polymorph. Subsequent experiments show that, whilst initially stable for 12 days, this may be a case of disappearing polymorphism.

Glycolide (1,4 dioxane-2,5-dione) is an important molecule as it is the precursor to the biodegradable polymer polyglycolic acid (PGA) and one of the monomers involved in poly(lactic-co-glycolic) acid (PLGA). Both of these polymers are of great interest in the areas of controlled drug delivery and other biomedical applications. ${ }^{1,2}$ PGA has commonly been used in bio-absorbable sutures, such as Dexon ${ }^{\circledR}$ for several decades, ${ }^{3,4}$ and has also found applications as tissue engineering scaffolds ${ }^{5}$ and food packaging materials ${ }^{6}$ (Krehalon®). There are several examples of PLGA-based drug delivery systems already on the market, such as Lupron Depot ${ }^{\circledR}$, Risperidal ${ }^{\circledR}$ Consta $^{\mathrm{TM}}$ and Arestin ${ }^{\circledR} .^{7}$ Polymerisation of these materials usually occurs through the use of catalysts and solvothermal routes which provides a consistent product that has defined physical properties that are beneficial to their applications.

Another route by which polymerisation can occur is through the use of pressure. Many studies have investigated

\footnotetext{
${ }^{a}$ Strathclyde Institute of Pharmacy and Biomedical Sciences, University of Strathclyde, 161 Cathedral Street, Glasgow, G4 ORE, UK. E-mail: ian.hutchison@strath.ac.uk, iain.oswald@strath.ac.uk

${ }^{b}$ Centre for Science at Extreme Conditions and School of Engineering, University of Edinburgh, Erskine Williams Building, The King's Buildings, Mayfield Road, Edinburgh, EH9 3FD, UK

${ }^{c}$ Dept. of Micro- and Nanotechnology Colloids and Biological Interfaces, Building 423, 2800 Kgs. Lyngby, Denmark

$\dagger$ Electronic supplementary information (ESI) available: The electronic supplementary information contains experimental procedures on Raman spectroscopy, single crystal and powder X-ray diffraction measurements, large volume press experiments including schematic diagram, and theoretical calculations including conformational analysis and pixel calculations. CCDC 10435741043575. For ESI and crystallographic data in CIF or other electronic format see DOI: $10.1039 / \mathrm{c} 5 \mathrm{ce} 00119 \mathrm{f}$
}

the use of pressure to induce the polymerisation of small molecule systems. ${ }^{8-10}$ Recently our group has been investigating the polymerisation process of small organic molecules using high pressure techniques with a view that the solidstate structure, i.e. polymorph, may alter the resulting polymeric structure and/or inhibit the reaction. ${ }^{11,12}$ In expansion of this work, we started to investigate the possibility of inducing ring-opening polymerisation under high pressure (as seen in carnosine $\mathrm{c}^{13}$ ).

Glycolide (Fig. 1) is a 6-membered ring structure formed via dehydration of glycolic acid, and has shown only one polymorphic form under ambient conditions. ${ }^{14}$ It is wellknown that small molecules exhibit polymorphism under high pressure conditions ${ }^{15-19}$ and that ring opening can occur. ${ }^{13}$ As such we chose to explore whether glycolide would exhibit polymorphism at high pressure with subsequent ring opening polymerisation to form a novel polymer structure as observed in other systems. ${ }^{9,11}$

Using a Merrill-Bassett diamond anvil cell (DAC), ${ }^{20,21}$ the behaviour of glycolide under hydrostatic conditions was studied up to $8 \mathrm{GPa}$, using in situ Raman spectroscopy. During this experiment part of the crystal was crushed into a polycrystalline sample which gave a different spectrum to the single crystal when a pressure of $0.58 \mathrm{GPa}$ was applied. At $0.40 \mathrm{GPa}$, the low pressure form was successfully refined, whilst at $0.58 \mathrm{GPa}$ the data was of too poor quality to solve the structure, illustrating that the crystal underwent a reconstructive phase transition in this pressure range. Some of the key differences that were observed were in the $\mathrm{CH}$ stretch

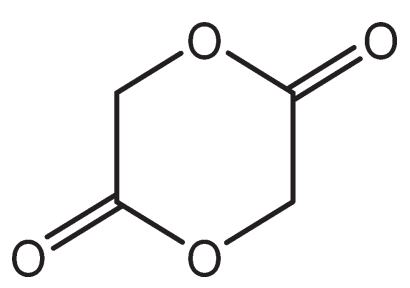

Fig. 1 Chemical structure of glycolide. 


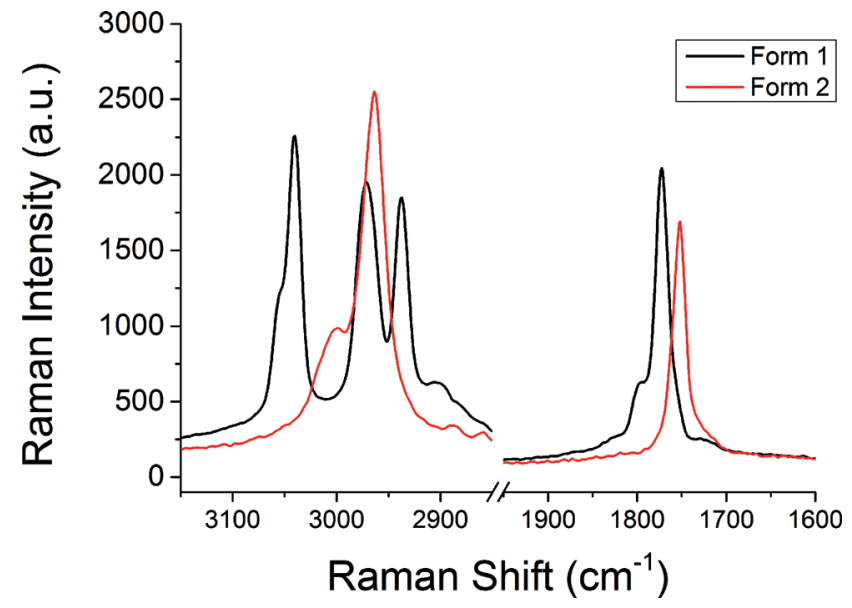

Fig. 2 Raman spectra of Forms 1 and 2 of glycolide, focussing on the $\mathrm{C}-\mathrm{H}$ stretch region and the ester-linkage region.

(3100-2900 $\mathrm{cm}^{-1}$ ) and the ester linkage regions (1900-1600 $\mathrm{cm}^{-1}$ ) (Fig. 2) suggesting that a conformational change to a higher molecular symmetry had occurred or that the new form possesses fewer independent molecules to describe the crystal structure. A separate study of glycolide powder under non-hydrostatic conditions up to $8 \mathrm{GPa}$ displayed no further significant changes in the Raman spectra obtained showing that polymerisation did not occur under either hydrostatic or non-hydrostatic conditions. In all experiments, the Raman pattern of the high-pressure form did not change upon decompression to ambient pressure and appeared stable for at least 2 days. Only a few cases have been reported of the recovery of high-pressure forms of organic species compared with the inorganic solid state. The most notable results being that of GABA monohydrate (seeding), ${ }^{22}$ and paracetamol (DAC and large-volume press recovery). ${ }^{23,24}$

The persistence of the high-pressure form of glycolide to ambient pressure and the low pressure of transformation highlighted the possibility of conducting large scale highpressure production of this polymorph. With this in mind, large volume (LV) experiments were conducted using a hydraulic press designed and built by the Kamenev group at the University of Edinburgh (for a detailed description of the press, see ESI $\dagger$ ). At the heart of this cell is a PTFE capsule (i.d. $8 \mathrm{~mm}$; length $60 \mathrm{~mm}$ ), that can hold up to $\sim 3 \mathrm{~cm}^{3}$ of liquid which can be compressed to $\sim 0.8 \mathrm{GPa}$. For our experiment, a $1.5 \mathrm{~g}$ sample of glycolide was placed into a PTFE capsule, with the remaining volume being filled with petroleum ether as the pressure-transmitting medium (PTM). The capsule was sealed at both ends using a PTFE cap and wrapped in PTFE tape to ensure a proper seal. After the assembly of the pressure cell was complete, it was placed in a hydraulic press and a load of 5 tons was applied, which is equivalent to $0.6 \mathrm{GPa}$. The sample was left at high pressure for approximately 24 hours. After this time, the load was decreased and the sample recovered to ambient pressure and filtered over a Buchner funnel before analysis using Raman spectroscopy which showed that it was Form 2. The recovered material was subsequently used to seed crystal growth from a saturated solution in acetone, and the resulting crystals were analysed via spectroscopic and X-ray diffraction techniques. These crystals were stable for up to 12 days.

Single crystals of diffraction quality were obtained from the seeding experiments and analysed. The data, collected at $293 \mathrm{~K}$, confirmed that a new polymorph had been formed, herein designated Form $2 . \$$ Form 2 is observed in orthorhombic $P b c a$ with unit cell dimensions $a=5.2400(2) \AA, b=$ 7.4389(3) $\AA$ and $c=11.7763(4) \AA$ ( $c f$. Form 1, in monoclinic $P 2_{1} / n$, with unit cell parameters $a=6.710 \AA, b=14.959 \AA$, $c=9.621 \AA$, and $\left.\beta=98.93^{\circ}\right) ;{ }^{14}$ the refinement details can be found in the ESI. $\dagger$ Form 2 crystallises with one molecule sitting on an inversion centre as opposed to the two molecules observed in Form 1. The increase in the crystal and molecular symmetry that was alluded to via the Raman spectra is confirmed with the diffraction experiment. The molecule undergoes a significant conformational change during the phase transition from a twist-boat conformation to a near-planar ring structure. Projection of the Form 1 molecules along the methylene groups conveys a V-configuration that distorts considerably over the phase transition (Fig. 3c \& d). The least-squares planes (1: O4, C3, O8, C5 and $\mathrm{C} 2$; and 2: $\mathrm{C} 2, \mathrm{C} 5, \mathrm{C} 6, \mathrm{O} 1$ and $\mathrm{O} 7$ ) are observed to be at an angle of $\sim 144^{\circ}$ to each other in both molecules, whereas this angle is increased to $\sim 173^{\circ}$ in Form 2 . The change in

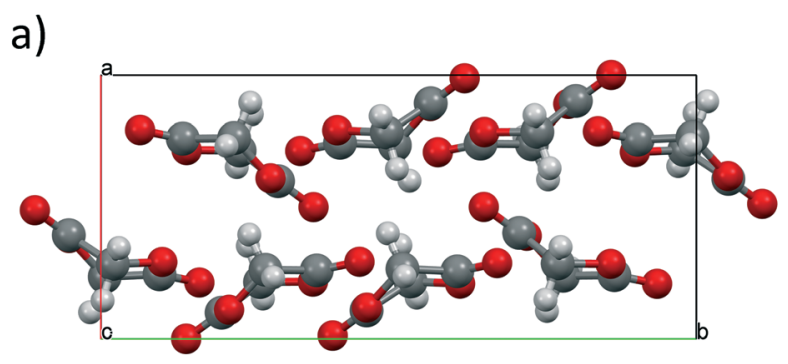

b)

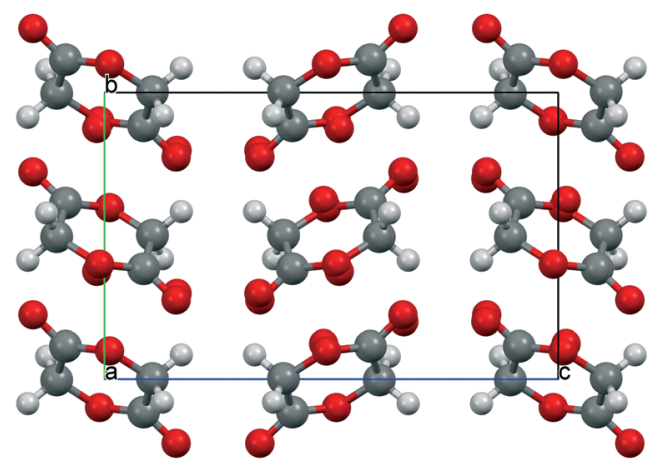

c)

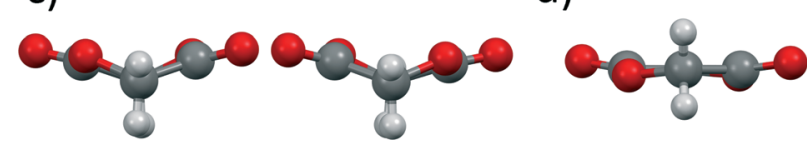

Fig. 3 Packing diagrams of a) Form 1 and b) Form 2 of glycolide. c) The two molecules in Form 1 exhibit a highly puckered twist-boat conformation whilst d) the molecule in Form 2 is almost planar. 
relative energies of this conformational change has been calculated using Gaussian 09 to be $-30 \&-40 \mathrm{~kJ} \mathrm{~mol}^{-1}$ from each molecule in Form $1 .^{25}$ The model and ring puckering analysis portrays a pseudo-chair conformation due to the inversion centre, but it is unlikely that this is the true conformation of the molecule. Calculation of the energy of a planar structure gave an energy barrier of $\sim 70$ and $\sim 60 \mathrm{~kJ} \mathrm{~mol}^{-1}$ (using the molecules in the Form 1 as a reference). Due to the modest pressures that glycolide was subjected to, the likely structure remains the twist-boat conformation albeit being less puckered. Fig. $3 \mathrm{~d}$ is a representation of our hypothesised conformation (that violates the crystal symmetry) however the disorder present within the model provides the necessary symmetry equivalent atoms.

To ensure that the recrystallised form was the same as that obtained at pressure a sample of glycolide powder, crushed between two glass slides to ensure small and uniform particle size, was analysed via Raman spectroscopy. This softer method of sample preparation was used to ensure the sample remained crystalline and was of the same polymorph. After confirming that this was the case, the powder was loaded into a DAC along with petroleum ether and the pressure increased to $0.20 \mathrm{GPa}$. The sample was left at this pressure for approximately 54 hours, and re-analysed via Raman spectroscopy. The Raman pattern matched the previously-observed patterns of Form 2 while the pressure had dropped to $0.12 \mathrm{GPa}$. A PXRD pattern was collected and a Pawley fit was performed using the unit cell parameters of the recrystallised Form 2 (see Fig. 4).

To quantify the energy difference between the two polymorphs, PIXEL calculations were performed using Form 1 and a modified model of Form $2 .^{26,27}$ PIXEL requires a full molecule to be present to perform the calculation, and so the symmetry of the crystal was reduced to meet this criterion. This requirement aids us in our interpretation of the crystal structure. For these calculations we were able to choose the atoms that best represented the assumed boat conformation rather that the symmetry-imposed chair conformation. Using this model the total energies for Forms 1 and 2 were -79.1 and $-89.0 \mathrm{~kJ} \mathrm{~mol}{ }^{-1}$, respectively. These values represent the intermolecular energy only and do not consider the conformational energy change between forms. As one can observe, for this conformation, Form 2 is more stable with respect to intermolecular energies. The change in $Z^{\prime}$ does pose a small problem with regard to the calculation of the conformational energy changes. The molecules in Form 1 are 30 and $40 \mathrm{~kJ} \mathrm{~mol}^{-1}$ more stable than the conformation of Form 2, as calculated using Gaussian. ${ }^{26}$ To the best approximation we have halved each value and summed them to give an approximate change in conformational energy to be $+35 \mathrm{~kJ} \mathrm{~mol}^{-1}$. Therefore, the energy change is $25 \mathrm{~kJ} \mathrm{~mol}^{-1}$ in favour of Form 1, hence Form 2 is the metastable form. Dunitz and Gavezzotti provided evidence that higher density polymorphs are not necessarily the most stable form and glycolide seems to be another example of this. ${ }^{27}$ The calculated densities of Forms 1 and 2 are $1.619 \mathrm{~g} \mathrm{~cm}^{-3}$ and $1.680 \mathrm{~g} \mathrm{~cm}^{-3}$, respectively, as summarised in Table S1.†

A further three LV experiments were conducted to ensure the tractable nature of the high pressure form as well as its stability at ambient pressure. Our initial experiment had shown that the Form 2 was stable for two days however we wished to confirm the rate of conversion with PXRD measurements. The first of these runs showed that the powder produced from the pressure experiment was a mixture of Forms 1 and 2 within an hour of decompression (Fig. S2 $\dagger$ ). However, two subsequent attempts (during one of which, the sample particle size was reduced by grinding prior to loading into the LV press at $0.54 \mathrm{GPa}$ for approximately 54 hours) yielded pure Form 1. This is very surprising given the fact that we were able to recrystallise Form 2 from acetone and that these crystals were stable for 12 days. There are two explanations for this behaviour; firstly, the conversion from Form 1 to Form 2 was not complete in the cases of the latter large volume experiments. Secondly, the environment and equipment had been contaminated with seeds of Form 1 and so any sort of manipulation of the solid after the initial experiments results in the conversion to the more stable form.

The first explanation can be rationalised from the previous DAC experiment where the polycrystalline part of the sample converted whilst the large crystal remained in Form 1. This provides evidence that the crystallite size is critical for the conversion to the new form, with smaller particle sizes providing more nucleation sites for the phase transition to occur. However in the last LV experiment we ensured that the crystals were lightly ground before loading but this did not yield a positive result.

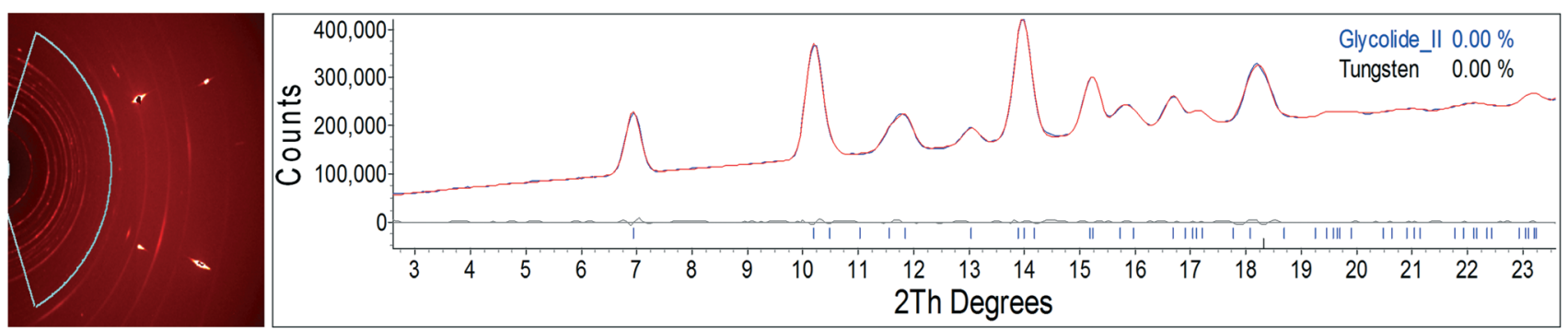

Fig. 4 Diffraction image (left) and powder diffraction pattern (right) of glycolide Form 2. The bright spots in the diffraction image are caused by the diamonds of the DAC. The diffraction rings at high 2-theta angle are caused by the tungsten gasket. The Pawley fit of the data fits very well with the calculated pattern from the single crystal data $\left(R_{\mathrm{wp}}=0.79 \%\right)$. 
It appears, then, that this may be another case of disappearing polymorphism where our lab environment, including diffractometer and large volume press, has been contaminated with seeds of Form 1 leading to instant conversion to the more stable form. ${ }^{28}$ To confirm this disappearing polymorph effect, further experiments in other "uncontaminated" laboratories and environments would need to be conducted. ${ }^{29,30}$

In this paper, we have shown the ability to isolate a new polymorph of glycolide at high pressure, recover this to ambient pressure in large scale, and we have been able to seed crystallisation experiments under ambient pressure. Glycolide has shown a large conformational change at relatively low pressures but there was no observation of polymerisation through the application of pressure. The change in behaviour of this form with successive experiments shows that this may be another example of disappearing polymorphism.

\section{Acknowledgements}

We would like to thank Angelo Gavezzotti for his useful discussions around the PIXEL calculations. We would like to thank Alastair Florence for his helpful comments and to the EPSRC Centre for Innovative Manufacturing in Continuous Manufacturing and Crystallisation for the use of their X-ray powder diffractometer. We would also like to thank the Leverhulme Trust and EPSRC for funding.

\section{Notes and references}

$\$$ Crystal data Form 1 at ambient pressure, CCDC deposition number 1043574: $\mathrm{C}_{4} \mathrm{H}_{4} \mathrm{O}_{4}, M=116.07, a=6.7039$ (2), $b=14.9481$ (4), $c=9.6177$ (2) $\AA, \beta=$ 98.9365(18) ${ }^{\circ}, V=952.10(4) \AA^{3}, T=296(2) \mathrm{K}$, space group $P 2_{1} / n, Z=8$, calculated density $=1.619 \mathrm{~g} \mathrm{~cm}^{-3}, 9333$ reflections measured, 2092 independent reflections $\left(R_{\text {int }}=0.027\right)$. The final $R_{1}$ value was $0.045(I>2 \sigma(I))$. The final $\mathrm{w} R\left(F^{2}\right)$ value was 0.123 (all data). Crystal data Form 2 at ambient pressure, CCDC deposition number 1043575: $\mathrm{C}_{4} \mathrm{H}_{4} \mathrm{O}_{4}, M=116.07, a=5.2400$ (2), $b=7.4389$ (3), $c=11.7763$ (4), $V=459.04(3) \AA^{3}, T=293(2) \mathrm{K}$, space group $P b c a, Z=4$, calculated density = $1.679 \mathrm{~g} \mathrm{~cm}^{-3}, 7121$ reflections measured, 470 independent reflections $\left(R_{\text {int }}=\right.$ $0.036)$. The final $R_{1}$ value was $0.042(I>2 \sigma(I))$. The final $w R\left(F^{2}\right)$ value was 0.093 (all data).

1 I. Bala, S. Hariharan and M. N. V. R. Kumar, Crit. Rev. Ther. Drug Carrier Syst., 2004, 21, 387-422.

2 R. A. Jain, Biomaterials, 2000, 21, 2475-2490.

3 J. H. Solhaug and P. Heimann, Acta Chir. Scand., 1975, 141, 326-328.

4 C. K. S. Pillai and C. P. Sharma, J. Biomater. Appl., 2010, 25, 291-366.

5 R. M. Day, A. R. Boccaccini, S. Shurey, J. A. Roether, A. Forbes, L. L. Hench and S. M. Gabe, Biomaterials, 2004, 25, 5857-5866.

6 S. A. Miller, ACS Macro Lett., 2013, 2, 550-554.

7 R. C. Mundargi, V. R. Babu, V. Rangaswamy, P. Patel and T. M. Aminabhavi, J. Controlled Release, 2008, 125, 193-209.

8 C. Murli and Y. Song, J. Phys. Chem. B, 2010, 114, 9744-9750.
9 D. Chelazzi, M. Ceppatelli, M. Santoro, R. Bini and V. Schettino, J. Phys. Chem. B, 2005, 109, 21658-21663.

10 M. Ceppatelli, M. Santoro, R. Bini and V. Schettino, J. Chem. Phys., 2000, 113, 5991-6000.

11 B. F. Johnston, W. G. Marshall, S. Parsons, A. J. Urquhart and I. D. H. Oswald, J. Phys. Chem. B, 2014, 118, 4044-4051.

12 I. D. H. Oswald and A. J. Urquhart, CrystEngComm, 2011, 13, 4503-4507.

13 C. Murli, A. K. Mishra, S. Thomas and S. M. Sharma, J. Phys. Chem. B, 2012, 116, 4671-4676.

14 N. Y. Belenkaya, B. G. Belsky, V. K. Dementev, A. I. Sakharova and V. I. Chernikova, Crystallogr. Rep., 1997, 42, 449.

15 D. I. A. Millar, I. D. H. Oswald, C. Barry, D. J. Francis, W. G. Marshall, C. R. Pulham and A. S. Cumming, Chem. Commun., 2010, 46, 5662-5664.

16 N. Satthaphut, O. B. Sutcliffe and I. D. H. Oswald, Z. Kristallogr. - Cryst. Mater., 2014, 229, 101-111.

17 F. P. A. Fabbiani, D. R. Allan, W. I. F. David, A. J. Davidson, A. R. Lennie, S. Parsons, C. R. Pulham and J. E. Warren, Cryst. Growth Des., 2007, 7, 1115-1124.

18 E. Patyk, J. Skumiel, M. Podsiadlo and A. Katrusiak, Angew. Chem., Int. Ed., 2012, 51, 2146-2150.

19 Y. V. Seryotkin, T. N. Drebushchak and E. V. Boldyreva, Acta Crystallogr., Sect. B: Struct. Sci., Cryst. Eng. Mater., 2013, 69, 77-85.

20 L. Merrill and W. A. Bassett, Rev. Sci. Instrum., 1974, 45, 290-294.

21 S. A. Moggach, D. R. Allan, S. Parsons and J. E. Warren, J. Appl. Crystallogr., 2008, 41, 249-251.

22 F. P. A. Fabbiani, G. Buth, D. C. Levendis and A. J. Cruz-Cabeza, Chem. Commun., 2014, 50, 1817-1819.

23 E. V. Boldyreva, T. P. Shakhtshneider, H. Ahsbahs, H. Sowa and H. Uchtmann, J. Therm. Anal. Calorim., 2002, 68, 437-452.

24 I. D. H. Oswald, I. Chataigner, S. Elphick, F. P. A. Fabbiani, A. R. Lennie, J. Maddaluno, W. G. Marshall, T. J. Prior, C. R. Pulham and R. I. Smith, CrystEngComm, 2009, 11, 359-366.

25 M. J. Frisch, G. W. Trucks, H. B. Schlegel, G. E. Scuseria, M. A. Robb, J. R. Cheeseman, G. Scalmani, V. Barone, B. Mennucci, G. A. Petersson, H. Nakatsuji, M. Caricato, X. Li, H. P. Hratchian, A. F. Izmaylov, J. Bloino, G. Zheng, J. L. Sonnenberg, M. Hada, M. Ehara, K. Toyota, R. Fukuda, J. Hasegawa, M. Ishida, T. Nakajima, Y. Honda, O. Kitao, H. Nakai, T. Vreven, J. A. Montgomery, J. E. Peralta, F. Ogliaro, M. Bearpark, J. J. Heyd, E. Brothers, K. N. Kudin, V. N. Staroverov, R. Kobayashi, J. Normand, K. Raghavachari, A. Rendell, J. C. Burant, S. S. Iyengar, J. Tomasi, M. Cossi, N. Rega, J. M. Millam, M. Klene, J. E. Knox, J. B. Cross, V. Bakken, C. Adamo, J. Jaramillo, R. Gomperts, R. E. Stratmann, O. Yazyev, A. J. Austin, R. Cammi, C. Pomelli, J. W. Ochterski, R. L. Martin, K. Morokuma, V. G. Zakrzewski, G. A. Voth, P. Salvador, J. J. Dannenberg, S. Dapprich, A. D. Daniels, Ö. Farkas, J. B. Foresman, 
J. V. Ortiz, J. Cioslowski and D. J. Fox, Gaussian, Inc., Wallingford, CT, 2009.

26 A. Gavezzotti, J. Phys. Chem. B, 2003, 107, 2344-2353.

27 J. D. Dunitz and A. Gavezzotti, J. Phys. Chem. B, 2012, 116, 6740-6750.
28 J. D. Dunitz and J. Bernstein, Acc. Chem. Res., 1995, 28, 193-200.

29 J. Webb and B. Anderson, J. Chem. Educ., 1978, 55, 644.

30 P. Bombicz, M. Czugler, R. Tellgren and A. Kálmán, Angew. Chem., Int. Ed., 2003, 42, 1957-1960. 